\title{
Hubungan Mutu Pelayanan dengan Minat Memanfaatkan Ulang Pelayanan Kesehatan di Puskesmas Tamalanrea Kota Makassar
}

\author{
The Relationship of Service Quality with the Interest to Reutilize Health Services in \\ Tamalanrea Puskesmas, Makassar City
}

Nining Ade Ningsih, Hasmah, Agustina Veronika Bhebhe

Program Studi Kesehatan Masyarakat, STIK Tamalatea Makassar, Makassar

\begin{abstract}
Abstrak
Tujuan dari penelitian ini adalah untuk menganalisis hubungan mutu pelayanan yang terdiri dari 5 dimensi (tangible, reliability, responsiveness, assurance dan empathy) dengan minat memanfaatkan ulang pelayanan kesehatan. Penelitian ini adalah observasional analitik dengan rancangan "Cross Sectional Study".Penelitian ini dilaksanakan di Puskesmas Tamalanrea Kota Makassar pada Juli-Agustus 2019. Sampel dalam penelitian ini sebanyak 64 orang dengan teknik accidental sampling. Sumber data menggunakan data primer dan data sekunder. Data dianalisis dengan uji chi square untuk melihat hubungan antara variabel independen dengan variabel dependen. Hasil penelitian menunjukkan bahwa semua variabel independen (dimensi mutu pelayanan) berhubungan dengan variabel minat memanfaatkan ulang pelayanan kesehatan. Mutu pelayanan berdasarkan dimensi tangible, reliability, assurance, empath berhubungan dengan minat memanfaatkan ulang pelayanan kesehatan dengan nilai $p=0,000$; dimensi responsiveness juga berhubungan dengan minat memanfaatkan ulang pelayanan kesehatan dengan nilai $p=0,000$.
\end{abstract}

Kata Kunci: Mutu Pelayanan, Minat Memanfaatkan Ulang, Pelayanan Kesehatan

\begin{abstract}
The purpose of this study is to analyze the relationship between service quality which consists of 5 dimensions (tangible, reliability, responsiveness, assurance and empathy) with the interest in reusing health services. This research is an analytic observational with the design of "Cross Sectional Study". This research was carried out at the Tamalanrea Health Center Makassar City from July to August 2019. The sample in this study was 64 people with accidental sampling technique. Sources of data used both primary data and secondary data. The data were analyzed by chi square test to see the relationship between the independent variable and the dependent variable. The result of this research showed that all independent variables (dimensions of service quality) were related to the variable of interest in reusing health services. Service quality based on tangible, reliability, assurance, empathy dimensions was related to the interest in reusing health services with $p$ value $=0.000$; the responsiveness dimension was also related to the interest in reusing health services with a $p$ value $=0.000$.
\end{abstract}

Keywords: Service Quality, Interest in Reuse, Health Services

Korespondensi: Nining Ade Ningsih

Email: niningadeningsih@stiktamalateamks.ac.id 


\section{PENDAHULUAN}

Keputusan Menteri Kesehatan Nomor 128 tahun 2004 bahwa Pusat Kesehatan Masyarakat atau Puskesmas sebagai Unit Pelaksana Teknis Dinas (UPTD) yaitu unit organisasi yang diberikan kewenangan kemandirian oleh dinas kesehatan kabupaten untuk melaksanakan tugastugas teknis operasional pembangunan kesehatan di wilayah kecamatan. Di dalam puskesmas terdapat 6 (enam) pokok upaya kesehatan yang wajib diselenggarakan oleh setiap puskesmas yang ada di wilayah Indonesia ${ }^{1}$. Menurut Peraturan Menteri Kesehatan Nomor 75 Tahun 2014, Pusat Kesehatan Masyarakat (Puskesmas) adalah fasilitas pelayanan kesehatan yang menyelenggarakan upaya kesehatan masyarakat dan upaya kesehatan perseorangan tingkat pertama, dengan lebih mengutamakan upaya promotif dan preventif, untuk mencapai derajat kesehatan masyarakat yang setinggi-tingginya di wilayah kerjanya ${ }^{2}$.

Sejak tahun 2013 jumlah puskesmas semakin meningkat dari 9.655 unit menjadi 9.825 unit pada tahun 2017. Sulawesi Selatan sendiri jumlah puskesmas sebanyak 448 puskesmas yang terdiri dari puskesmas rawat inap sebanyak 227 dan puskesmas non rawat inap sebanyak 221. Dari hasil pengisian instrumen self assessment oleh Puskesmas, pada tahun 2017 terdapat 3.225 Puskesmas yang telah memberikan pelayanan sesuai standar, dari 3.392 Puskesmas yang telah melaporkan ke pusat, 111 diantaranya adalah puskesmas yang berada di Sulawesi Selatan. ${ }^{3}$

Puskesmas Tamalanrea merupakan salah satu puskesmas yang ada di Provinsi Sulawesi Selatan. Jumlah pengunjung di Puskesmas Tamalanrea pada tahun 2017 adalah sebesar 34.865 jiwa, dengan rincian sebagai berikut: peserta Askes sebesar 6.658 jiwa, BPJS sebesar 7.286 jiwa, Jamkesmas sebesar 2.545, jiwa dan peserta umum sebesar 8.624 $4^{4}$. Pada tahun 2018 jumlah pengunjung di Puskesmas Tamalanrea yaitu sebesar 17.489 jiwa dengan rincian sebagai berikut : peserta Askes sebanyak 6.989 jiwa, BPJS sebanyak 7.725 jiwa, dan peserta Jamkesmas sebesar 2.775 jiwa. Dalam kurun waktu satu tahun terjadi penurunan jumlah pengunjung yang sangat signifikan $^{5}$.

Salah satu faktor yang menyebabkan minat memanfaatkan ulang pelayanan kesehatan adalah 5 (lima) dimensi yang dikembangkan oleh Zeithaml yaitu : tangible, reliability, responsiveness, assurance, dan empathy. Berdasarkan penelitian yang dilakukan oleh Regina Pajow dkk di Puskesmas Sonder didapatkan bahwa terdapat hubungan antara responsiveness, assurance, dan empathy dengan minat pemanfaatan kembali Puskesmas Solder ${ }^{6}$. Penelitian oleh Nur Fajri Istiqomah di Puskesmas II Tambak mendapatkan ada hubungan tangible, reliability, responsiveness, assurance, dan empathy dengan minat kunjungan ulang pasien ${ }^{7}$. Sedangkan penelitian oleh Susy Sriwahyuni Sukiswo di Puskesmas Sangkalan mendapatkan bahwa ada hubungan responsiveness, assurance, empathy, reliability dengan minat kunjungan ulang ${ }^{8}$.

Tujuan dari penelitian ini adalah untuk menganalisis hubungan mutu pelayanan yang terdiri dari 5 dimensi : bukti Langsung (tangible) berupa penampilan, sarana dan prasarana fisik, peralatan dan berbagai materi komunikasi beserta keadaan lingkungan di sekitarnya; kehandalan (reliability) berupa kemampuan pemberi jasa untuk memberikan pelayanan sesuai dengan harapan pelanggan yang terpercaya, akurat, konsisten tanpa adanya kesalahan, bersikap simpatik dan akurasi tinggi; ketanggapan (responsiveness) yaitu pemberi jasa untuk melayani pasien 
dengan cepat serta adanya kemauan untuk mendengar dan mengatasi keluhan yang diajukan pasien, dalam hal kesiapan dan kecepatan pemberi jasa dalam melayani, serta penanganan keluhan pelanggan; jaminan (assurance) yaitu pemberi jasa untuk mampu menimbulkan keyakinan dan kepercayanan kepada pasien terhadap janji yang telah disampaikan, seperti pengetahuan pemberi jasa terhadap produk-produk yang akan pasien gunakan, keramahtamahan, simpati, dan sopan dalam memberi pelayanan, memberikan informasi yang jelas, kemampuan untuk menanamkan dan meyakinkan kepada pasien untuk merasa aman dalam memanfaatkan pelayanan yang telah diberikan; empati (empathy) yaitu ketersediaan pemberi jasa untuk memberikan perhatian khusus kepada pasien dengan berusaha memahami keinginan atau harapan pasien, sehingga diharapkan dapat memahami kebutuhan dari pasien secara spesifik.

\section{METODE}

Penelitian ini adalah observasional analitik dengan rancangan "Cross Sectional Study". Studi Cross Sectional adalah suatu rancangan atau desain yang menjelaskan dinamika korelasi antara variabel independen dengan variabel dependen pada saat yang bersamaan (point time approach). Penelitian ini dilaksanakan di Puskesmas Tamalanrea Kota Makassar pada JuliAgustus 2019. Sampel dalam penelitian ini sebanyak 64 orang dengan teknik accidental sampling. Sumber data menggunakan data primer dan data sekunder. Data dikumpulkan dengan menggunakan Kuesioner dengan menyusun daftar pertanyaan terstruktur berkaitan dengan variabel penelitian yang selanjutnya disebarkan kepada responden. Pengolahan data yang dilakukan meliputi editing, coding, data entry, tabulating dan diolah dengan komputer program SPSS yang disajikan dalam bentuk tabel distribusi frekuensi dan tabulasi silang. Analisis data yang dilakukan meliputi analisis univariat untuk mendapatkan gambaran umum dengan cara mendeskripsikan tiap-tiap variabel yang digunakan dalam penelitian yaitu gambaran distribusi frekuensi dalam bentuk tabel, analisis bivariat untuk mengetahui hubungan antara variabel independen dan variabel dependen dengan menggunakan uji chi square.

\section{HASIL PENELITIAN}

\section{Karakteristik Responden}

\section{Umur}

Tabel 1. Distribusi Responden menurut Umur di Puskesmas Tamalanrea Kota Makassar Tahun 2019

\begin{tabular}{ccc}
\hline Umur (Tahun) & Frekuensi (n) & Persentase (\%) \\
\hline $15-20$ & 11 & 17.2 \\
$21-25$ & 21 & 32.8 \\
$26-30$ & 10 & 15.6 \\
$31-35$ & 5 & 7.8 \\
$36-40$ & 4 & 6.3 \\
$41-45$ & 5 & 7.8 \\
$46-50$ & 6 & 9.4 \\
$51-55$ & 2 & 3.1 \\
Total & 64 & 100.0 \\
\hline
\end{tabular}


2. Jenis Kelamin

Tabel 2. Distribusi Responden menurut Jenis Kelamin di Puskesmas Tamalanrea Kota Makassar Tahun 2019

\begin{tabular}{lcc}
\hline Jenis Kelamin & Frekuensi (n) & Persentase (\%) \\
\hline Laki-laki & 17 & 26.6 \\
Perempuan & 47 & 73.4 \\
\hline Total & 64 & 100.0 \\
\hline Sumber : data primer, 2019 &
\end{tabular}

\section{Pendidikan Terakhir}

Tabel 3. Distribusi Responden menurut Pendidikan Terakhir di Puskesmas Tamalanrea

\begin{tabular}{lcc}
\multicolumn{3}{c}{ Kota Makassar Tahun 2019 } \\
\hline $\begin{array}{l}\text { Pendidikan } \\
\text { Terakhir }\end{array}$ & Frekuensi (n) & Persentase (\%) \\
\hline SD & 1 & 1.6 \\
\hline SMP/Sederajat & 7 & 10.9 \\
\hline SMA/Sederajat & 23 & 35.9 \\
\hline Perguruan Tinggi & 33 & 51.6 \\
\hline \multicolumn{1}{c}{ Total } & $\mathbf{6 4}$ & $\mathbf{1 0 0 . 0}$ \\
\hline
\end{tabular}

Sumber : data primer, 2019

Analisis Univariat

1. Bukti Langsung (Tangible)

Tabel 4. Distribusi Responden menurut Bukti Langsung (Tangible) di Puskesmas

Tamalanrea Kota Makassar Tahun 2019

\begin{tabular}{lcc}
\hline Bukti Langsung & Frekuensi (n) & Persentase (\%) \\
\hline Baik & 50 & 78.1 \\
\hline Tidak Baik & 14 & 21.9 \\
\hline Total & $\mathbf{6 4}$ & $\mathbf{1 0 0 . 0}$ \\
\hline Sumber : data primer, 2019 &
\end{tabular}

2. Kehandalan (Reliability)

Tabel 5. Distribusi Responden menurut Kehandalan (Reliability) di Puskesmas Tamalanrea Kota Makassar Tahun 2019

\begin{tabular}{lcc}
\hline Kehandalan & Frekuensi (n) & Persentase (\%) \\
\hline Baik & 55 & 85.9 \\
\hline Tidak Baik & 9 & 14.1 \\
\hline Total & $\mathbf{6 4}$ & $\mathbf{1 0 0 . 0}$ \\
\hline
\end{tabular}

Sumber : data primer, 2019 
3. Ketanggapan (Responsineness)

Tabel 6. Distribusi Responden menurut Ketanggapan (Responsineness) di Puskesmas

Tamalanrea Kota Makassar Tahun 2019

\begin{tabular}{lcc}
\hline Ketanggapan & Frekuensi (n) & Persentase (\%) \\
\hline Baik & 55 & 85.9 \\
\hline Tidak Baik & 9 & 14.1 \\
\hline Total & $\mathbf{6 4}$ & $\mathbf{1 0 0 . 0}$ \\
\hline Sul
\end{tabular}

Sumber : data primer, 2019

4. Jaminan (Assurance)

Tabel 7. Distribusi Responden menurut Jaminan (Assurance) di Puskesmas Tamalanrea Kota Makassar Tahun 2019

\begin{tabular}{lcc}
\hline Jaminan & Frekuensi (n) & Persentase (\%) \\
\hline Baik & 53 & 82.8 \\
\hline Tidak Baik & 11 & 17.2 \\
\hline Total & $\mathbf{6 4}$ & $\mathbf{1 0 0 . 0}$ \\
\hline
\end{tabular}

Sumber : data primer, 2019

5. Empati (Empathy)

Tabel 8. Distribusi Responden menurut Empati (Empathy) di Puskesmas Tamalanrea Kota Makassar Tahun 2019

\begin{tabular}{lcc}
\hline Empati & Frekuensi (n) & Persentase (\%) \\
\hline Baik & 53 & 82.8 \\
\hline Tidak Baik & 11 & 17.2 \\
\hline Total & $\mathbf{6 4}$ & $\mathbf{1 0 0 . 0}$ \\
\hline
\end{tabular}

Sumber : data primer, 2019

6. Minat Memanfaatkan Ulang Pelayanan Kesehatan

Tabel 9. Distribusi Responden menurut Minat Memanfaatkan Ulang Pelayanan Kesehatan di Puskesmas Tamalanrea Kota Makassar Tahun 2019

\begin{tabular}{lcc}
\hline $\begin{array}{l}\text { Minat Memanfaatkan } \\
\text { Ulang }\end{array}$ & Frekuensi (n) & Persentase (\%) \\
\hline Berminat & 51 & 79.7 \\
\hline Tidak Berminat & 13 & 20.3 \\
\hline Total & $\mathbf{6 4}$ & $\mathbf{1 0 0 . 0}$ \\
\hline
\end{tabular}

Sumber : data primer, 2019 
Analisis Bivariat

1. Hubungan Bukti Langsung (Tangible) dengan Minat Memanfaatkan Ulang Pelayanan Kesehatan

Tabel 10. Hubungan Bukti Langsung (Tangible) dengan Minat Memanfaatkan Ulang Pelayanan Kesehatan di Puskesmas Tamalanrea Kota Makassar

Tahun 2019

\begin{tabular}{lcccc}
\hline \multirow{2}{*}{$\begin{array}{l}\text { Bukti } \\
\text { Langsung }\end{array}$} & \multicolumn{2}{c}{ Minat Memanfaatkan Ulang } & \multirow{2}{*}{ Total } & p-value \\
\cline { 2 - 3 } & $\begin{array}{c}\text { Iya } \\
\mathbf{n}(\boldsymbol{\%})\end{array}$ & $\begin{array}{c}\text { Tidak } \\
\mathbf{n}(\boldsymbol{\%})\end{array}$ & & \\
\hline Baik & $48(96,0)$ & $2(4,0)$ & $50(78,1)$ & \multirow{2}{*}{0,0005} \\
Tidak Baik & $3(21,4)$ & $11(78,6)$ & $14(21,9)$ & \\
\hline \multicolumn{1}{c}{ Total } & $\mathbf{5 1 ( 7 9 , 7 )}$ & $\mathbf{1 3 ( 2 0 , 3 )}$ & $\mathbf{6 4 ( 1 0 0 )}$ & \\
\hline
\end{tabular}

Sumber : data primer, 2019

2. Hubungan Kehandalan (Reliability) dengan Minat memanfaatkan ulang Pelayanan Kesehatan

Tabel 11 Hubungan Kehandalan (Reliability) dengan Minat Memanfaatkan Ulang Pelayanan Kesehatan di Puskesmas Tamalanrea Kota Makassar

Tahun 2019

\begin{tabular}{lcccc}
\hline \multirow{2}{*}{ Kehandalan } & \multicolumn{2}{c}{ Minat Memanfaatkan Ulang } & Total & p-value \\
\cline { 2 - 3 } & $\begin{array}{c}\text { Iya } \\
\mathbf{n}(\boldsymbol{\%})\end{array}$ & $\begin{array}{c}\text { Tidak } \\
\mathbf{n}(\boldsymbol{\%})\end{array}$ & & \\
\hline Baik & $50(90,9)$ & $5(9,1)$ & $55(85,9)$ & \multirow{2}{*}{0,0005} \\
Tidak Baik & $1(11,1)$ & $8(88,9)$ & $9(14,1)$ & \\
\hline \multicolumn{1}{c}{ Total } & $\mathbf{5 1 ( \mathbf { 7 9 , 7 } )}$ & $\mathbf{1 3 ( 2 0 , 3 )}$ & $\mathbf{6 4}(\mathbf{1 0 0})$ & \\
\hline
\end{tabular}

Sumber : data primer, 2019

3. Hubungan Ketanggapan (Responsiveness) dengan Minat Memanfaatkan Ulang Pelayanan Kesehatan

Tabel 12 Hubungan Ketanggapan (Responsiveness) dengan Minat Memanfaatkan Ulang

Pelayanan Kesehatan di Puskesmas Tamalanrea Kota Makassar

Tahun 2019

\begin{tabular}{lcccc}
\hline \multirow{2}{*}{ Ketanggapan } & \multicolumn{2}{c}{ Minat Memanfaatkan Ulang } & \multirow{2}{*}{ Total } & \multirow{2}{*}{ p-value } \\
\cline { 2 - 3 } & $\begin{array}{c}\text { Iya } \\
\mathbf{n}(\boldsymbol{\%})\end{array}$ & $\begin{array}{c}\text { Tidak } \\
\mathbf{n}(\boldsymbol{\%})\end{array}$ & & \\
\hline Baik & $48(87,3)$ & $7(12,7)$ & & $55(85,9)$ \\
Tidak Baik & $3(33,3)$ & $6(66,7)$ & $9(14,1)$ & 0,001 \\
\hline \multicolumn{1}{c}{ Total } & $\mathbf{5 1 ( 7 9 , 7 )}$ & $\mathbf{1 3 ( 2 0 , 3 )}$ & $\mathbf{6 4}(\mathbf{1 0 0})$ & \\
\hline
\end{tabular}

Sumber : data primer, 2019 
4. Hubungan Jaminan (Assurance) dengan Minat Memanfaatkan Ulang Pelayanan Kesehatan

Tabel 13 Hubungan Jaminan (Assurance) dengan Minat Memanfaatkan Ulang Pelayanan Kesehatan di Puskesmas Tamalanrea Kota Makassar

Tahun 2019

\begin{tabular}{|c|c|c|c|c|}
\hline \multirow[b]{2}{*}{ Jaminan } & \multicolumn{2}{|c|}{ Minat Memanfaatkan Ulang } & \multirow[t]{2}{*}{ Total } & \multirow{2}{*}{ p-value } \\
\hline & $\begin{array}{c}\text { Iya } \\
\text { n }(\%)\end{array}$ & $\begin{array}{l}\text { Tidak } \\
\text { n }(\%)\end{array}$ & & \\
\hline Baik & $50(94,3)$ & $3(5,7)$ & $53(82,8)$ & \multirow{3}{*}{0,0005} \\
\hline Tidak Baik & $1(9,1)$ & $10(90,9)$ & $11(17,2)$ & \\
\hline Total & $51(79,7)$ & $13(20,3)$ & $64(100)$ & \\
\hline
\end{tabular}

Sumber : data primer, 2019

5. Hubungan Empati (Empathy) dengan Minat Memanfaatkan Ulang Pelayanan Kesehatan

Tabel 14 Hubungan Empati (Empathy) dengan Minat Memanfaatkan Ulang Pelayanan Kesehatan di Puskesmas Tamalanrea Kota Makassar

Tahun 2019

\begin{tabular}{|c|c|c|c|c|}
\hline \multirow[b]{2}{*}{ Empati } & \multicolumn{2}{|c|}{ Minat Memanfaatkan Ulang } & \multirow[t]{2}{*}{ Total } & \multirow[t]{2}{*}{ p-value } \\
\hline & $\begin{array}{c}\text { Iya } \\
\text { n }(\%)\end{array}$ & $\begin{array}{l}\text { Tidak } \\
\text { n }(\%)\end{array}$ & & \\
\hline Baik & $48(96,0)$ & $5(9,4)$ & $53(82,8)$ & \\
\hline Tidak Baik & $3(21,4)$ & $8(72,7)$ & $11(17,2)$ & 0,0005 \\
\hline Total & $51(79,7)$ & $13(20,3)$ & $64(100)$ & \\
\hline
\end{tabular}

Sumber : data primer, 2019

\section{PEMBAHASAN}

Karaktertik umum responden merupakan ciri khas pasien yang menjadi responden pada penelitian ini. Karakteristik responden mencakup umur, jenis kelamin dan pendidikan terakhir. Sedangkan variabel independen adalah tangible, reliability, responsiveness, assurance, dan empathy serta variabel dependen adalah minat memanfaatkan ulang pelayanan kesehatan.

Responden pada karakteristik umur terbanyak adalah kategori 21-25 tahun, hal ini menandakan bahwa responden kebanyakan berada pada usia produktif. Sedangkan jenis kelamin terbanyak pada responden perempuan dan karakteristik pendidikan terbanyak pada pendidikan perguruan tinggi. Berdasarkan karakteristik tersebut dapat dikatakan bahwa responden pada penelitian ini memiliki latar belakang misalnya dengan pendidikan tinggi sehingga dapat memberikan jawaban terkait minat memanfaatkan ulang pelayanan kesehatan di Puskesmas Tamalanrea Kota Makassar.

Hubungan Mutu Pelayanan berdasarkan Dimensi Tangible dengan Minat Memanfaatkan Ulang Pelayanan Kesehatan

Berdasarkan dimensi tangible didapatkan jawaban responden terbanyak pada kategori baik dan pada minat memanfaatkan ulang pelayanan kesehatan juga terbanyak pada kategori 
berminat. Berdasarkan hasil uji chi square didapatkan ada hubungan Mutu Pelayanan berdasarkan Dimensi Tangible dengan Minat Memanfaatkan Ulang Pelayanan Kesehatan dengan nilai $p=0.000$. Hasil penelitian ini tidak sejalan dengan penelitian oleh Regina dkk (2017) ${ }^{6}$ dengan nilai $p$ lebih dari nilai $\alpha$ yang berarti tidak ada hubungan antara bukti langsung (tangible) dengan minat pemanfaatan kembali pelayanan kesehatan. Selain itu, penelitian ini juga sejalan dengan Susy Sriwahyuni Sukiswo $(2018)^{8}$ yang menunjukkan bahwa ada hubungan bermakna antara bukti fisik dengan minat kunjungan ulang dengan $p$ value $=0,011$.

Bukti fisik/ bukti langsung (tangible) dapat berupa ketersediaan sarana dan prasarana termasuk alat yang siap pakai serta penampilan karyawan/ staf yang menyenangkan. Pada penelitian ini didapatkan bahwa sebagian besar responden menyatakan bukti langsung (tangible) berada pada kategori baik yang terdiri dari kelengkapan dan kebersihan peralatan, kebersihan dan kenyamanan ruang perawatan, ruang tunggu dan lainnya nyaman dan layak digunakan, serta penampilan para tenaga kesehatan yang rapid an bersih. Hal ini juga tentunya yang dapat menyebabkan minat kunjungan ulang pelayanan kesehatan pada puskesmas.

Penelitian Halimatus'adiah (2015) ${ }^{9}$ juga membuktikan bahwa adanya hubungan antara persepsi pasien tentang daya bukti langsung pelayanan dengan minat kunjungan ulang di Puskesmas Ciputat Timur. Hal ini juga sesuai dengan sebagaimana yang dikemukakan oleh Zeithmall dalam Halimatus'adiah (2015) menyatakan bahwa kebersihan unit ruang perawatan, kebersihan kamar mandi, kerapihan dan penampilan dokter, kebersihan makanan yang disajikan, kebersihan dan kelengkapan alat-alat medis serta kenyamanan puskesmas merupakan faktor yang penting dipertimbangkan pasien untuk kembali lagi.

\section{Hubungan Mutu Pelayanan berdasarkan Dimensi Reliability dengan Minat Memanfaatkan Ulang Pelayanan Kesehatan}

Mutu pelayanan berdasarkan dimensi kehandalan (reliability) berdasarkan jawaban responden terbanyak pada kategori baik. Hasil uji chi square menunjukkan bahwa ada hubungan antara dimensi reliability dengan minat pemanfaatan ulang pelayanan kesehatan dengan nilai $p$ $=0.000$. Penelitian ini tidak sejalan dengan yang dilakukan oleh Helmawati dan Handayani $(2014)^{10}$ yang mendapatkan bahwa tidak ada hubungan antara reliability dengan minat kunjungan ulang pasien. Kemampuan dalam memberikan pelayanan kesehatan dengan akurat dan tepat waktu merupakan salah satu penyebab pasien melakukan kunjungan ulang.

Menurut Nursalam (2011) ${ }^{11}$, setiap pelayanan dan tindakan yang dilakukan perawat memerlukan pelayanan yang handal, artinya dalam memberikan pelayanan setiap perawat diharapkan memiliki kemampuan dalam pengetahuan, keahlian, kemandirian, penguasaan dan profesionalisme kerja yang tinggi, sehingga aktivitas kerja yang dilakukan menghasilkan bentuk pelayanan yang memuaskan tanpa adanya

\section{Hubungan Mutu Pelayanan berdasarkan Dimensi Responsiveness dengan Minat Memanfaatkan Ulang Pelayanan Kesehatan}

Mutu pelayanan berdasarkan dimensi responsiveness terbanyak pada kategori baik. Hasil uji chi square didapatkan bahwa ada hubungan antara dimensi responsiveness dengan minat pemanfaatan ulang pelayanan kesehatan dengan nilai $p=0.001$. Ketanggapan (responsiveness) 
merupakan suatu kemauan untuk membantu dan memberikan pelayanan dalam hal ini pelayanan kesehatan yang cepat dan tepat melalui penyampaian informasi yang jelas. Membiarkan pasien menunggu tanpa alasan yang jelas menjadi salah satu penyebab timbulnya pendapat yang negatif atau kurang baik dalam mutu pelayanan, yang tentu saja dapat menurunkan minat kunjungan ulang bagi pasien. Hasil penelitian ini sejalan dengan penelitian yang dilakukan oleh Anggraini dkk. (2012) ${ }^{12}$ di Kota Semarang yang menunjukkan bahwa terdapat hubungan yang bermakna antara pelayanan yang diberikan oleh petugas kesehatan dengan minat kunjungan ulang pada pelayanan kesehatan dengan nilai $p=0,000$.

\section{Hubungan Mutu Pelayanan berdasarkan Dimensi Assurance dengan Minat Memanfaatkan Ulang Pelayanan Kesehatan}

Mutu pelayanan berdasarkan dimensi assurance lebih banyak pada kategori baik. Hasil uji chi square juga menunjukkan ada hubungan antara dimensi assurance dengan minat memanfaatkan ulang pelayanan kesehatan dengan nilai $p=0.000$. Hasil penelitian ini sejalan dengan penelitian oleh Susy Sriwahyuni Sukiswo $(2018)^{8}$ yang menunjukkan bahwa hasil uji chi square menunjukkan terdapat hubungan bermakna antara jaminan dengan minat kunjungan ulang dengan $p$ value $=0,000$.

\section{Hubungan Mutu Pelayanan berdasarkan Dimensi Empathy dengan Minat Memanfaatkan Ulang Pelayanan Kesehatan}

Mutu pelayanan berdasarkan dimensi empathy lebih banyak pada kategori baik. Hasil uji chi square juga menunjukkan ada hubungan antara dimensi empathy dengan minat memanfaatkan ulang pelayanan kesehatan dengan nilai $p=0.000$. Dimensi ini terkait dengan kepedulian dan perhatian khusus petugas kesehatan kepada pasien dalam memahami kebutuhan mereka dan memberikan kemudahan untuk dihubungi ketika pasien membutuhkan bantuan. Penelitian ini sejalan dengan penelitian yang dilakukan oleh Adhyto et al. (2013) ${ }^{13}$ di Puskesmas Kabupaten Ngawi yang menunjukkan bahwa ada hubungan yang bermakna antara empati pelayanan kesehatan dengan minat kunjungan ulang dengan nilai $p=0,000$.

Kepedulian kepada pasien dalam memberikan pelayanan dapat berupa memberikan motivasi kepada pasien ataupun dorongan agar pasien semangat dalam pelayanan. Hal tersebut sangat penting untuk meningkatkan kepuasan pasien (Mosadeghrad, 2014) ${ }^{14}$.

\section{KESIMPULAN DAN SARAN}

Ada hubungan antara mutu pelayanan (semua dimensi) dengan minat memanfaatkan ulang pelayanan kesehatan di Puskesmas Tamalanrea Kota Makassar. Ada hubungan dimensi Bukti Langsung (Tangible) dengan Minat Memanfaatkan Ulang Pelayanan Kesehatan di Puskesmas Tamalanrea Kota Makassar dengan nilai $p=0.000$. Ada hubungan Kehandalan (Reliability) dengan Minat Memanfaatkan Ulang Pelayanan Kesehatan di Puskesmas Tamalanrea Kota Makassar dengan nilai $p=0.000$. Ada hubungan Ketanggapan (Responsiveness) dengan Minat Memanfaatkan Ulang Pelayanan Kesehatan di Puskesmas Tamalanrea Kota Makassar dengan nilai $p=0.001$. Ada hubungan Jaminan (Assurance) dengan Minat Memanfaatkan Ulang Pelayanan Kesehatan di Puskesmas Tamalanrea Kota Makassar dengan nilai $p=0.000$ dan ada 
hubungan Antara Empati (Empathy) dengan Minat Memanfaatkan Ulang Pelayanan Kesehatan di Puskesmas Tamalanrea Kota Makassar dengan nilai $p=0.000$.

Mutu pelayanan berdasarkan dimensi Bukti Langsung (Tangible), Kehandalan (Reliability), Ketanggapan (Responsiveness), Jaminan (Assurance), dan Empati (Empathy) perlu ditingkatkan dengan memberikan pelatihan-pelatihan serta melakukan monitoring dan evaluasi kepada petugas kesehatan secara berkala demi peningkatan mutu pelayanan kepada pasien.

\section{DAFTAR PUSTAKA}

1. Menteri Kesehatan Republik Indonesia. 2004. Keputusan Menteri Kesehatan Republik Indonesia Nomor 128/Menkes/SK/II/2004 tentang Kebijakan Dasar Pusat Kesehatan Masyarakat Menteri Kesehatan Republik Indonesia. Jakarta.

2. Menteri Kesehatan Republik Indonesia. 2014. Peraturan Menteri Kesehatan Republik Indonesia Nomor 75 Tahun 2014 tentang Pusat Kesehatan Masyarakat. Jakarta.

3. Kementerian Kesehatan Republik Indonesia. 2018. Profil Kesehatan Indonesia tahun 2017. Jakarta.

4. Puskesmas Tamalanrea. 2018. Profil Puskesmas Tamalanrea tahun 2017.

5. Puskesmas Tamalanrea. 2019. Profil Puskesmas Tamalanrea tahun 2018.

6. Regina V.M. Pajow dkk. 2017. Hubungan antara Kualitas Jasa Pelayanan Kesehatan dengan Minat Pemanfaatan Kembali di Puskesmas Sonder. Fakultas Kesehatan Masyarakat. Universitas Sam Ratulangi.

7. Nur Fajri Istiqomah. Hubungan Mutu Pelayanan terhadap Minat Kunjungan Ulang Pasien Rawat Inap di Puskesmas II Tambak Kabupaten Banyumas 2015. Jurnal Ilmu Kesehatan Masyarakat. Universitas Negeri Semarang.

8. Susy Sriwahyuni Sukiswo. 2018. Hubungan Kepuasan Pasien Dengan Minat Kunjungan Ulang Di Puskesmas Sangkalan Kecamatan Susoh Kabupaten Aceh Barat. Jurnal Fakultas Kesehatan Masyarakat, Vol. 5 No. 1 tahun 2018.

9. Halimatus'adiah, 2015. Hubungan Persepsi Pasien Terhadap Mutu Pelayanan Dengan Minat Pemanfaatan Rawat Jalan Umum Di Puskesmas Ciputat Timur. Skripsi. Program Studi Kesehatan Masyarakat UIN Syarif Hidayatullah. Jakarta.

10. Helmawati T. dan Handayani, S.D. 2014. Pengaruh Kualitas Layanan Terhadap Minat Kunjungan Ulang Yang Dimediasi Oleh Kepuasan Di Klinik Rumah Zakat Yogyakarta. Jurnal. Program Studi Manajemen Rumah Sakit. Universitas Muhammadiyah Yogyakarta.

11. Nursalam, 2011. Manajemen Kesehatan: Aplikasi dalam Praktik Keperawatan.

12. Anggraini, M.T. 2012. Kepuasan Pasien dengan Minat dalam Pemanfaatan Ulang Yankes pada Praktek Dokter Keluarga. Jurnal Universitas Muhammadiyah Semarang, 154-161.

13. Adhytyo, 2013. Realibilitas mempengaruhi kepuasan pasien terhadap pelayanan kesehatan di salah satu puskesmas Ngawi. Gaster 10 (2):2

14. Mosadeghrad, A. M. 2014. Factors Influencing Health care Service Quality. International Journal of Health Policy and Management, 3(2), 77-89. 